\title{
Care For Small Babies: A DOH Policy-in-waiting
}

Caring for preterm and low birthweight babies, collectively termed 'small babies,' has long been the predicament of perinatal and neonatal medicine experts throughout the world. Its occurrence is, by and large, associated with maternal morbidities, which consequently contribute to neonatal mortality and morbidity, both in the short and long term. For this reason, its prevention and optimal management remain a challenge and the subject of much deliberation, research, policy and even, legislation.

Traditionally kept in incubators for long periods, small premature babies grow in this environment; not much different from 'poultry hatcheries' where the environment is artificially controlled, and nurturing is programmed. The shortage of incubators in an overcrowded Colombian neonatal intensive care unit (NICU) turned out to be a blessing-in-disguise for Dr. Edgar Rey Sanabria, ${ }^{1}$ who recognized that such an environment only led to more unwanted complications and even death. Taking the cue from the kangaroo and other marsupials, he transferred the caring of stable small babies from incubators to their mothers' chests and valiantly sent them home earlier than the standard recommendation, with the mothers' breastmilk and warmth to nurture and care for them. This innovation which took place in the 1970s, took 15 years for the scientific community to take notice after the first scientific evidence was published in the literature. ${ }^{2}$ This landmark study and all those that followed, consistently showed the impact of kangaroo mother care (KMC) on neonatal mortality, growth, neurodevelopment, and overall wellness of the mother-baby dyad in the company of a supportive family, decreased postpartum anxiety and depression, improved breastfeeding exclusivity and duration, decreased NICU sepsis rates ${ }^{3,4}$ with no increase in community-acquired infections. ${ }^{2}$ Amidst the shortage of NICU nursing personnel, the other significant 'side-effect' of the KMC intervention is the improved allocation of NICU nursing and auxiliary personnel to high-risk neonates with the integration of the mother in the overall care of the small baby, a prelude to the concept of family-centered/ integrated NICU care currently being recommended. ${ }^{5}$

KMC in the Philippines started in 1999 at the Dr. Jose Fabella Memorial Hospital, after two of its personnel received training in Colombia (Fundacion Canguro). Its standard implementation as a hospital policy of care for small babies soon followed the first local in-house publication of data ${ }^{6}$ showing its favorable impact on mortality and overall outcomes on its population of preterm small babies. Involvement of the community of Manila through the city health government improved follow-up and ambulatory KMC implementation. ${ }^{7}$ By 2005, the nidus of a comprehensive KMC program implementation was realized and technically ready for replication in other health facilities caring for preterm and small babies. Such endeavor, however, was not possible at the time.

The KMC Foundation Philippines, registered in 2008, helped pave the way for KMC acceleration in the country. This followed the issuance of the DOH Administrative Order 2009-0025 in Dec 2009 on the essential newborn care (ENC) protocol, which included initiation of $\mathrm{KMC}$ for small babies at birth, for better thermoregulation and maternal-infant bonding. The KMC Foundation offered the complete program concept to regional DOH facilities and helped establish regional KMC Centers of Excellence nationwide. Between 2012 and 2014, the foundation gained the support and collaboration of development partners in the Philippines, i.e., the World Health Organization, UNICEF, Save The Children/USAID, and most importantly, the Family Health Office of the Department of Health. ENC, basic newborn resuscitation, and $\mathrm{KMC}$ integration into the Care for Small Babies (CSB) package of interventions, henceforth, was cascaded to all $\mathrm{DOH}$ facilities. ${ }^{8}$ Capacity-building efforts have led to the establishment of $27 \mathrm{CSB}$ centers for training and excellence and 195 program-implementing facilities nationwide by the end of 2018 .

The first draft of the DOH Policy on CSB, entitled "National Policy on the Quality of Care for Small Babies: Accelerating the Reduction of Newborn Deaths" was composed in 2015. Included in this policy, are 1) capacity development of health care providers 2) provision of a KMC unit within the NICU complex or Pediatrics ward and 3) networking with the community through the service delivery network and collaboration with local government units. The initial draft fueled the constitution of a PhilHealth Z-benefit package for the care of preterm and small babies which was launched in 2016 and initiated by 2017 in the established CSB Centers of Excellence. The draft policy has been revised in a workshop in 2019.5 
While so much has happened on the ground level towards the acceleration and efficient implementation of the CSB package of interventions, the DOH policy that should reinforce its standard practice in all of 1,871 PhilHealth-accredited facilities nationwide, remains in the shadows, awaiting an official stamp of approval.

This focused Acta Medica Philippina special issue on KMC highlights the research evidence generated by various institutions currently implementing the standard program in the Philippines. It is hoped that this publication will help substantiate and facilitate the approval of the pending $\mathrm{DOH}$ policy on care for small babies.

\author{
Socorro De Leon-Mendoza, MD, FPPS, FPSNbM \\ President, Kangaroo Mother Care Foundation Philippines, Inc. \\ Immediate Past President, Federation of Asia and Oceania Perinatal Societies
}

\title{
REFERENCES
}

1. Rey SE, Martínez HG. Rational management of the premature child. Fetal Medicine Course. Bogotá: National University; 1983. p. 137-15.

2. Charpak N, Ruiz-Peláez JG, Charpak Y. Rey-Martinez Kangaroo Mother Program: an alternative way of caring for low birth weight infants? One year mortality in a two cohort study. Pediatrics. 1994 Dec; $94(6$ Pt 1):804-10. PMID: 7970993.

3. Conde-Agudelo A, Díaz-Rossello JL. Kangaroo mother care to reduce morbidity and mortality in low birthweight infants. Cochrane Database Syst Rev. 2016 Aug 23; 2016(8):CD002771. doi: 10.1002/14651858.CD002771.pub4. PMID: 27552521.

4. Charpak N, Tessier R, Ruiz JG, Hernandez JT, Uriza F, Villegas J, et al. Twenty-year follow-up of kangaroo mother care versus traditional care. Pediatrics. 2017 Jan; 139(1):e20162063. doi: 10.1542/peds.2016-2063. Epub 2016 Dec 12. PMID: 27965377.

5. USAID. Every Preemie: Nurturing Care for Small and Sick Newborns. Evidence Review and Country Case Studies. Eds. New K, Durairaj A, Robb-McCord J, Khadka N. Aug 2019. pp54-62 [Internet]. 2021 [cited October 2021]. Available from: https://www.everypreemie.org/wp-content/ uploads/2019/09/Nurturing-Care-Evidence-Review-and-Case-Studies-13Aug2019.pdf

6. De Leon-Mendoza S. Impact of kangaroo mother care (KMC) on the survivability of the moderately-low birth weight neonate. Dr. Jose Fabella Memorial Hospital Medical J. 2001; 2:1

7. Bergh AM, de Graft-Johnson J, Khadka N, Om'Iniabohs A, Udani R, Pratomo H, et al. The three waves in implementation of facility-based kangaroo mother care: a multi-country case study from Asia. BMC Int Health Hum Rights. 2016 Jan 27; 16:4. doi: 10.1186/s12914-016-0080-4. PMID: 26818943.

8. Calibo AP, De Leon Mendoza S, Silvestre MA, Murray JCS, Li Z, Mannava P, et al. Scaling up kangaroo mother care in the Philippines using policy, regulatory and systems reform to drive changes in birth practices. BMJ Glob Health. 2021 Aug; 6(8):e006492. doi: 10.1136/bmjgh-2021-006492. PMID: 34417273. 